\title{
INOVAÇÃO CURRICULAR E FÍSICA MODERNA: DA PRESCRIÇÃO À PRÁTICA
}

\author{
Marcília Barcellos* \\ Andreia Guerra** $^{* *}$
}

RESUMO: Pretende-se analisar a criação e a realização de uma proposta com vistas a implementar a mudança prescrita por um documento oficial e trabalhar a Teoria da Relatividade Restrita em sala de aula, principalmente por parte do protagonista da mudança, o professor. Nesse sentido, a pesquisa visa construir subsídios para responder à questão: Como um professor sensibilizado com a implementação da prescrição de um currículo diferenciado ressignifica e reconstrói o novo currículo a partir de sua prática docente? Para tal, desenvolvemos uma pesquisa qualitativa e, mais especificamente, um Estudo de Caso. A análise dos dados mostrou que a situação particular da pesquisa permitiu ao professor analisado construir novos significados à mudança prescrita, elegendo ênfases e omissões determinantes aos objetivos educacionais em questão.

Palavras-Chave: Ensino de Física. Física Moderna e Contemporânea. Currículo.

\section{CURRICULAR INNOVATION AND MODERN PHYSICS: FROM PRESCRIPTION TO PRACTICE}

ABSTRACT: This study aims to discuss the construction and implementation of a proposition to implement a mandatory curricular recommendation and to teach the Special Theory of Relativity in class, with focus on the protagonist of the change: the teacher. Therefore, this study aims to give subsidies to answer the question: how does a teacher who wants to implement the prescribed differentiated curriculum uses his teaching practice to reconstruct and re-signify the new curriculum? To answer this question, we developed qualitative research, specifically a Case Study. The analysis of the data indicate that context of development of this study, where the teacher participated as an author of the pedagogical process, allowed him to reconstruct the curriculum, choosing what issues should be highlighted and abandoned to achieve the pedagogical objectives.

Keywords: Physics Teaching. Modern and Contemporary Physics. Curriculum.

\footnotetext{
* Doutora em Ensino de Ciências (Área de concentração: Física) pela Universidade de São Paulo. Atualmente é docente do Centro Federal de Educação Tecnológica Celso Suckow da Fonseca, no Campus de Petrópolis (CEFET-RJ). E-mail: marcilia12@hotmail.com.

* Doutora em História e Filosofia da Ciência na Engenharia de Produção pela Universidade Federal do Rio de Janeiro (UFRJ). Professora e pesquisadora do Centro Federal de Educação Tecnológica de Celso Suckow da Fonseca (CEFET-RJ) é bolsista produtividade 2 do $\mathrm{CNPq}$. E-mail: aguerra@tekne.pro.br.
}

DOI - http://dx.doi.org/10.1590/1983-21172015170203 


\section{INNOVACIÓN CURRICULAR Y FÍSICA MODERNA: DE LA PRESCRIPCIÓN A LA PRÁCTICA}

Resumen: El artículo pretende analizar la creación y realización de una propuesta con el objetivo de implementar el cambio prescrito por un documento oficial y trabajar la Teoría de la Relatividad Especial en aula, principalmente por parte del protagonista del cambio: el maestro. La investigación visa construir subsidios para responder a la cuestión: ¿Cómo un maestro sensibilizado con la interpretación de la prescripción de un currículo diferenciado resignifica y reconstruye el nuevo currículo a partir de su práctica docente? Desarrollamos una investigación cualitativa y, más específicamente, un Estudio de Caso. El análisis de los datos mostró que la situación particular de la investigación permitió al maestro analizado construir nuevos significados al cambio prescripto, eligiendo énfasis y omisiones determinantes a los objetivos educacionales en cuestión.

Palabras clave: Enseñanza de Física. Física Moderna y Contemporánea. Currículo. 


\section{INTRODUCุÃO}

Há décadas a comunidade de pesquisa em Ensino de Física aponta a necessidade de inovações, transformações e melhorias no ensino praticado na grande maioria das escolas brasileiras. Embora as compreensões não sejam homogêneas, assim como os indicativos e o entendimento sobre o que constituem "melhorias" e sobre o que deveria ser o Ensino de Física, há uma tendência que se consolidou bastante, principalmente nas últimas décadas: a inserção da Física Moderna e Contemporânea (FMC) no Ensino Médio (EM).

Apesar de a defesa da inserção de FMC não ser recente, existem diferentes propostas e pressupostos (tanto explícitos quanto implícitos) dos trabalhos que discutem a FMC no EM (VALENTE et al., 2007). Não há consenso, por exemplo, se o trabalho em sala de aula em torno dos temas de FMC deve ser integrado ao estudo da Física Clássica, ou se deve ser trabalhado separadamente, sem referências à Física Clássica (SILVA; ALMEIDA, 2011). Destacam-se, ainda, as diferentes abordagens que aparecem nos estudos que discutem propostas pedagógicas concretas de inserção de FMC na educação básica. Nessa perspectiva, há os que defendem uma abordagem CTS, aqueles que propõem uma abordagem histórico-filosófica entre outros (EIJKELHOF; KORTLAND; LOO, 1984; PINTO; ZANETIC, 1999; SOUZA; ARAÚJO, 2010; MORAIS; GUERRA, 2013).

As divergências apontadas não impediram, entretanto, que a introdução de temas e conteúdos de FMC na educação básica se fizesse presente nos documentos oficiais como currículos, diretrizes e parâmetros e, também, nos manuais didáticos, estes pressionados principalmente por avalições de cunho nacional, como o Programa Nacional do Livro Didático (PNLD).

Documentos oficiais como os Parâmetros Curriculares Nacionais (PCN) incorporam essa tendência, já analisada e mencionada em vários artigos (SILVA; ARENGHI; LINO, 2013). Acrescentamos a esse cenário o Currículo Mínimo de Física do Estado do Rio de Janeiro (CMF) implementado em 2012. Esse documento, como mostra a análise de Lutz, Barcellos e Guerra (2012), está em consonância tanto com os PCN, quanto com os resultados da pesquisa em ensino que indicam que o trabalho com FMC deve ser integrado ao da Física Clássica. Dessa forma, essa proposta curricular traz a FMC ao longo de todos os três anos do EM.

Esse novo currículo delineou um contexto de mudança no Estado do Rio de Janeiro, na qual o ensino da FMC, antes ausente no currículo estadual, representa uma proposta de inovação e uma ruptura com modelos tradicionais já bastante consolidados.

Do nosso ponto de vista, analisar um contexto de mudança curricular requer um olhar amplo que busque levar em conta outros fatores para além de se inserir ou retirar tal ou qual conteúdo. É preciso levar em conta as finalidades implícitas e explícitas inerentes a uma mudança curricular e como os sujeitos envolvidos reagem e participam desse processo (BARCELLOS, 2013).

Em Lutz, Barcellos e Guerra (2012) exploramos a dimensão documental des- 
sa mudança, especialmente no que concerne à FMC, mostrando que há uma ruptura considerável em relação aos pressupostos presentes no currículo anterior. Segundo essa análise, o currículo anterior apresenta uma lista de tópicos, exclusivamente de Física Clássica, e na justificativa da organização do mesmo afirma-se não ser possível trabalhar temas de FMC no EM (LUTZ et al., 2012, p. 8). Além da proposta de inserção de temas de FMC nas três séries do EM, o CMF (2012) difere-se do anterior por buscar organizar os conteúdos com base em competências e habilidades, apresentando um alinhamento em relação aos PCN.

Entendendo que a prescrição documentada é apenas parte de um processo de mudança curricular e que os sujeitos envolvidos e protagonistas da mudança não apenas a incorporam ou rejeitam, mas também a ressignificam (LOPES, 2008), no presente estudo, voltamos nossos olhares para os professores e suas práticas.

O trabalho de Monteiro (2013) acompanhou as expectativas e as práticas de um professor experiente frente a esse novo currículo. Sua análise retratou um professor otimista que aprova o novo currículo e que, no entanto, apresentou várias dificuldades ao trabalhar temas de FMC. O trecho a seguir relata sua dificuldade com o tema da Relatividade:

[...] Esse foi o primeiro ano de implantação do Currículo Mínimo, ainda é muito cedo para ter uma opinião formada no todo, mas eu digo o seguinte: foi a melhor experiência que eu tive nos 40 anos de magistério na parte de Física. O Currículo Mínimo permitiu contextualizar a Física [...]. Eu não gostei de Relatividade no primeiro ano [...]. Essa é uma crítica que eu faço mais para mim do que para o Currículo Mínimo. Eu vou ter que mudar a minha estratégia. (MONTEIRO, 2013, p. 35)

Uma das questões destacadas por esse professor foi a falta de material de apoio disponível que lhe fornecesse subsídios para o trabalho com a Teoria da Relatividade Restrita (TRR) em sala de aula. A visão desse professor pode sugerir que o fornecimento de conteúdos de FMC e caminhos para trabalhar tais conteúdos aos professores é garantia de sucesso da implementação do novo currículo. Diante desse cenário, o presente artigo visa trazer subsídios para reflexões em torno de questões relacionadas a implementações de novos currículos, a partir da análise da criação e da realização de uma proposta para implementar a mudança prescrita no Currículo Mínimo do Estado do Rio de Janeiro e trabalhar a TRR em sala de aula, tanto por parte do protagonista da mudança, o professor, quanto dos outros sujeitos envolvidos no processo.

\section{ALGUNS RECORTES TEÓRICOS}

Primeiramente é preciso entender o que caracteriza o contexto dessa pesquisa para além de um relato de experiência no qual um jovem professor enfrenta desafios e supera dificuldades em suas práticas.

O contexto delimitado pela pesquisa é um contexto de reforma curricular. E, nesse sentido, o intuito dessa pesquisa dialoga com aportes teóricos da área de currí- 
culo. Esse entendimento se alicerça na concepção de que uma proposição de mudança pretendida por alguma instância não se esgota na prescrição corporificada no currículo. A prescrição é apenas parte de um processo que se recria na prática, entendida como espaço de recontextualização e ressignificação como define Bernstein (1996), no qual os verdadeiros protagonistas da mudança, que, segundo Goodson (2008), são os professores, darão rumos decisivos ao processo.

Embora o caráter prescritivo do currículo seja extremamente presente e marcante, há de se reconhecer, principalmente a partir das teorias de currículo, que há uma dinâmica complexa, rica e vasta, que transcende essa faceta.

Essa faceta prescritiva, intrinsecamente ligada aos primórdios do conceito currículo, foi por muito tempo enfatizada, inclusive de forma utilitária, na construção de currículos, propostas e projetos educacionais. Autores como Tyler (1989) e Bruner (1987) deixaram marcas tecnicistas importantes no campo. Do ponto de vista desses autores, um currículo deve definir objetivos educacionais a serem atingidos a partir de conteúdos a serem ensinados e ainda descrever uma maneira eficaz de avaliar se os objetivos definidos foram atingidos ou não. No caso da obra de Bruner é marcante ainda a relevância das áreas científicas como referência na definição do como ensinar.

Há de se reconhecer que o currículo escolar coloca saberes a serviço de finalidades. Segundo as vertentes mais técnicas, das quais Ives Chevalard (1998) é um ícone, o conhecimento escolar se constitui como algo próprio, distinto, mas que tem sua referência de origem no saber acadêmico. Desse ponto de vista, os saberes que serão ensinados na escola são delimitados por instâncias que transcendem a escola. A professores e a estudantes cabe a tarefa de executar, ainda que com certo grau de liberdade, o currículo prescrito para tal ou qual disciplina.

Um dos problemas mais latentes inerentes a essa visão tecnicista é o fato de que as previsões e expectativas criadas a partir de uma prescrição, muitas e muitas vezes, não se verificam. Embora o caminho natural seja culpar os executores pela aplicação inadequada do projeto idealizado, muitas críticas e questionamentos emergiram e apontaram para caminhos de superação desse modelo.

Essa superação culminou, inclusive, no chamado paradigma da prática (SCHÖN, 1983; TARDIF, 2010), cunhando termos como professor reflexivo e professor pesquisador, que, de diferentes formas, defende uma visão da ação do professor que vai além da de um aplicador de técnicas. Nesse paradigma se reconhece que o professor enfrenta, na sua prática, problemas e situações não ordinárias que exigem uma resposta rápida, criativa, da qual ele é autor e executor.

Do ponto de vista das teorias de currículo, justamente uma das facetas que são negligenciadas pela visão tecnicista, segundo Lopes e Macedo (2011), é a da dimensão da prática, ou seja, do que efetivamente acontece na escola. Isso porque tal ou qual proposta curricular é produzida em um contexto, mas as experiências curriculares, no sentido das experiências pedagógicas de ensino e aprendizagem, vão muito além das atividades planejadas nos documentos escritos.

E, nesse contexto pedagógico, novos significados são construídos a partir das experiências dos sujeitos. O local das práticas pedagógicas na maioria das vezes é muito 
distinto do contexto original de produção do documento, e isso abre espaço para um processo de recontextualização.

No processo de recontextualização, os agentes envolvidos produzem novos significados de acordo com suas experiências e expectativas. Assim, o currículo prescrito deixa de ser um fim e passa a ser apenas uma etapa de um processo complexo e criativo.

Segundo Goodson (2008), o protagonista das práticas escolares que se desencadeiam a partir de um currículo prescrito é o professor. O professor é o agente que pode aderir, abraçar e incorporar de maneira criativa uma proposta curricular ou simplesmente rechaçá-la levando-a ao fracasso. O que Goodson defende em última análise é a participação dos docentes nos próprios processos de confecção dos currículos. Isso porque, segundo ele, apenas se as propostas forem ao encontro de missões e expectativas pessoais dos professores, elas não serão rechaçadas.

No caso do nosso contexto de pesquisa, de um currículo de Física, na prática de um professor de Física em uma disciplina de Física, cabe ainda trazer alguns aportes teóricos sobre a própria organização do conhecimento de forma disciplinar e suas consequências.

Dentre as estruturas que sustentam a organização curricular disciplinar, sem dúvida, figura uma forte influência das áreas acadêmicas de referência. Para além das análises que enfatizam as influências dessas áreas na constituição, manutenção, estabilidade e mudança nos saberes escolares, as análises de cunho mais sociológico apontam outros elementos.

Para Goodson (2008), uma mudança curricular passa por distintos segmentos: desde discurso oficial, ou seja, do segmento externo que administra a mudança, passando pelo segmento interno, que é o ambiente escolar, até o segmento pessoal, no qual os indivíduos envolvidos trazem para a mudança suas crenças e missões pessoais.

Goodson (2008) aponta ainda como uma disciplina escolar é construída social e politicamente nas instituições escolares a partir de subgrupos e tradições. Nesse sentido, a Física, como uma área já consolidada e justificada, é mais próxima de padrões universitários vinculados à tradição mais acadêmica.

Isso corrobora a análise de Chervel (1992), que aponta para uma inevitável naturalização do conhecimento escolar. Para esse autor, as justificativas para ensinar tal ou qual conhecimento são aparentes, visíveis, apenas em momentos de reformas curriculares. Depois, naturalmente, as justificativas tendem ao esquecimento à medida que os conteúdos e métodos se consolidam como saber a ser ensinado no contexto escolar.

Nesse sentido, destacamos, também, a importância dos elementos da cultura escolar (FOURQUIN, 1993) dentre os quais estão os que compõem a identidade do professor, muito ligados aos conteúdos que o definem como professor de tal ou qual disciplina. Assim, a sequência dos conteúdos e sua organização estão no cerne da identidade docente e acabam parecendo uma forma "natural" de se estruturar o conteúdo, que não é, portanto, passível de questionamentos.

No contexto da Física, essas questões da cultura escolar se concretizam numa 
cultura didática da Física. Tal cultura inclui uma sequência de conteúdos bastante consolidada nos livros, uma abordagem com muitos exercícios, a predominância de verdades e certezas científicas, além de abordagens pseudo-históricas de fatos e personagens da ciência, restando pouco espaço para a contradição e a controvérsia entre diferentes modelos (MARTINS, 2007).

Essas reflexões conjugadas ao fato de as escolas estaduais do Rio de Janeiro estarem submetidas a um novo currículo que apresenta diferenças marcantes em relação ao anterior, seja na proposição de conteúdos novos, seja na forma de apresentação da matriz curricular, nos levaram a desenvolver a presente pesquisa. Tal pesquisa tem por objetivo construir subsídios que permitam responder à seguinte questão: Como um professor sensibilizado com a implementação da prescrição de um currículo diferenciado ressignifica e reconstrói o novo currículo a partir de sua prática docente?

\section{Contexto da pesquisa}

O contexto do desenvolvimento dessa pesquisa é marcado primeiramente pela implementação do CMF (2012). Os autores desse novo documento afirmam que ele se baseia nos PCN e que apresenta um projeto formativo fundamentado na formação para a cidadania. Fora isso, o documento declara apresentar os conteúdos, estruturado por competências e habilidades. O Quadro 1 mostra a estrutura disposta no documento para o primeiro ano do EM para os quatro bimestres.

Os resultados de pesquisa apresentados por Monteiro (2013) nos evidenciam a dificuldade de um professor em trabalhar a Teoria da Relatividade Restrita.

Quadro 1 - Habilidades e Competências [A12] do Currículo Mínimo de Física - $1^{\text {a }}$ série

\section{$1^{\circ}$ Bimestre - Cosmologia - Movimento}

Compreender o conhecimento científico como resultado de uma construção humana, inserido em um processo histórico e social.

- Reconhecer a importância da Física Aristotélica e a influência exercida sobre o pensamento ocidental, desde o seu surgimento até a publicação dos trabalhos de Isaac Newton.

- Reconhecer, utilizar, interpretar e propor modelos explicativos para fenômenos naturais ou sistemas tecnológicos.

- Saber comparar as ideias do Universo geostático de Aristóteles-Ptolomeu e heliostático de Copérnico-Galileu-Kepler.

- Conhecer as relações entre os movimentos da Terra, da Lua e do Sol para a descrição de fenômenos astronômicos (duração do dia/noite, estações do ano, fases da Lua, eclipses, marés etc.).

Reconhecer ordens de grandeza de medidas astronômicas.

- Compreender a relatividade do movimento.

Compreender fenômenos naturais ou sistemas tecnológicos, identificando e relacionando as grandezas envolvidas.

Compreender os conceitos de velocidade e aceleração associados ao movimento dos planetas.

- Reconhecer o caráter vetorial da velocidade e da aceleração. 


\section{$2^{\circ}$ Bimestre - Forças}

- Compreender o conhecimento científico como resultado de uma construção humana, inserido em um processo histórico e social.

- Reconhecer a importância da Física newtoniana e sua influência sobre o pensamento ocidental, tendo sido considerada a doutrina científica do lluminismo.

- Reconhecer, utilizar, interpretar e propor modelos explicativos para fenômenos naturais ou sistemas tecnológicos.

- Reconhecer o modelo das quatro forças fundamentais da natureza: força gravitacional, força eletromagnética, força nuclear forte e força nuclear fraca.

- Compreender as interações gravitacionais, identificando a força gravitacional e o campo gravitacional para explicar aspectos do movimento de planetas, cometas, satélites e naves espaciais.

- Perceber a relação entre causa, movimento e transformação de estado e as leis que regem o movimento.

- Caracterizar causas ou efeitos dos movimentos de partículas, substâncias, objetos ou corpos celestes.

- Compreender fenômenos naturais ou sistemas tecnológicos, identificando e relacionando as grandezas envolvidas.

- Perceber a relação algébrica de proporcionalidade direta com o produto das massas e inversa com o quadrado da distância da Lei da Gravitação Universal de Newton.

- Reconhecer a diferença entre massa e peso e suas unidades de medida.

- Compreender o conceito de inércia.

- Compreender que a ação da resultante das forças altera o estado de movimento de um corpo. - Compreender o princípio da ação e reação.

\section{$3^{\circ}$ Bimestre - Relatividade Restrita e Geral}

- Compreender o conhecimento científico como resultado de uma construção humana, inserido em um processo histórico e social.

- Compreender que a Teoria da Relatividade constitui um novo modelo explicativo para o universo e uma nova visão de mundo.

- Reconhecer, utilizar, interpretar e propor modelos explicativos para fenômenos naturais ou sistemas tecnológicos.

- Reconhecer os modelos atuais do universo levolução estelar, buracos negros, espaço curvo e big bang).

- Compreender que o tempo e o espaço são relativos devido à invariância da velocidade da luz.

- Reconhecer tecido espaço-tempo sendo o tempo a quarta dimensão.

- Construir conceito de energia.

- Identificar a relação entre massa e energia na relação $E=m \cdot c^{2}$

\section{$4^{\circ}$ Bimestre - Impulso, momento linear e conservação do momento}

- Compreender fenômenos naturais ou sistemas tecnológicos, identificando e relacionando as grandezas envolvidas.

Reconhecer as causas da variação de movimentos, associando as intensidades das forças ao tempo de duração das interações para identificar, por exemplo, que na colisão de um automóvel o cinto de segurança e o air bag aumentam o tempo de duração da colisão para diminuir a força de impacto sobre o motorista.

- Identificar regularidades, invariantes e transformações.

- Utilizar a conservação do momento linear e a identificação de forças para fazer análises, previsões e avaliações de situaç̃oes cotidianas que envolvem os movimentos.

- Reconhecer a conservação do momento linear e, por meio dela, as condições impostas aos movimentos. 
Já o trabalho de Lutz, Barcellos e Guerra (2013) corrobora a hipótese de que os subsídios para um professor que tenha a intenção de abordar temas de TRR no EM não sejam abundantes.

Assim, para responder à pergunta dessa pesquisa, construímos um grupo de trabalho que envolveu duas professoras pesquisadoras universitárias, uma aluna licencianda de Iniciação Científica e um professor da escola pública, o protagonista da pesquisa. Esse grupo de trabalho teve por propósito auxiliar o professor no preenchimento de uma das lacunas do processo de inovação curricular: a falta de subsídios para abordar o tema selecionado em sala de aula de nível médio.

O professor em questão, que denominaremos professor A, era recém-formado. Havia ao longo de sua licenciatura participado do Programa Institucional de Bolsa de Iniciação à Docência (PIBID). Como participante desse projeto, ele discutiu com seu grupo questões concernentes à cultura escolar de sua disciplina: a Física. Essa discussão ocorreu no momento em que o CMF (2012) fora implementado no Estado do Rio de Janeiro. O grupo do PIBID, do qual o professor A participava como licenciando, acompanhava o trabalho de um professor de Física, o professor supervisor do PIBID, que precisava pela primeira vez cumprir o CMF (2012). Esse professor de Física lecionava a disciplina há mais de 20 anos e nunca trabalhara FMC. Essa particularidade do grupo do PIBID fez com que muitas reuniões fossem dedicadas a discussões diferenciadas sobre como e por que ensinar FMC no EM. Nessas discussões foi problematizada, pelos professores universitários que acompanhavam o trabalho, a cultura didática da Física. O professor A, como integrante desse grupo e na condição de discente, além de ler e discutir textos, trabalhou junto com o professor supervisor na construção de aulas de um dos temas de FMC, energia nuclear, propostos pelo CMF.

Um ponto a ser destacado para a presente pesquisa é que o grupo do PIBID citado dedicou atenção à implementação do tema de FMC, porém, outra premissa explícita que atravessa todo o documento do CMF (2012), que é a contextualização histórica dos conteúdos, foi considerada menos relevante pelo grupo.

Ao finalizar a licenciatura, o professor A ingressou na rede pública estadual do Rio de Janeiro, tendo, portanto, a obrigatoriedade de implementar o CMF (2012) que havia não apenas discutido durante a licenciatura, como participado de parte de sua implementação junto com o professor supervisor do PIBID, na construção de práticas pedagógicas. Essa característica indicou ao grupo de pesquisa que acompanhar o professor A na implementação do CMF (2012), enquanto docente efetivo de uma escola, traria subsídios para responder à pergunta da presente pesquisa. Isso porque poderíamos trazer reflexões em torno do currículo, como as apontadas por Goodson (2008), no sentido de não apenas confrontar o segmento externo e o interno que administravam aquela mudança curricular, como o segmento pessoal. No segmento pessoal, poderíamos analisar como um docente, que durante sua formação básica discutiu elementos da cultura escolar de sua disciplina, enfrentava o desafio de implementar um currículo que se mostrava diferente 
e, portanto, não seguia a forma "natural" da disciplina Física e, assim, poderíamos analisar como ele ressignificaria a mudança curricular prescrita.

A partir dessa delimitação escolhemos desenvolver um Estudo de Caso com o referido professor. A opção pelo Estudo de Caso decorreu do fato de o mesmo ser apropriado para os estudos em que se tem um fenômeno social complexo (ANDRÉ, 1984). Em nosso caso, a ressignificação do currículo diante da cultura escolar da disciplina apresenta múltiplas variáveis, indicando a complexidade do fenômeno (ALVES-MAZOTTI, 2006). Fora isso, os percursos dessa pesquisa levaram-nos a uma investigação sistemática de uma instância específica, em nosso caso, um professor.

A escolha por um Estudo de Caso não implica em simplificações, mas ao contrário em um processo mais complexo. Isso porque se busca no caso uma apreensão mais completa do objeto, o que implica em não apenas considerar o professor em si, mas o contexto no qual ele se insere. Dessa forma, detalhes serão importantes com vistas a contextualizar as informações e situações retratadas (ANDRÉ, 1984; ALVES-MAZOT'TI, 2006).

Para construir a resposta à questão motivadora dessa pesquisa, utilizamo-nos como dados para a gravação em áudio e vídeo das aulas do professor, para as anotações das pesquisadoras das discussões implementadas pelo grupo de trabalho e para a descrição da participação do professor em atividades durante sua graduação. A triangulação desses dados permitiu construir análises geradoras de subsídios para responder à pergunta da pesquisa.

\section{GRUPO DE TRABALHO E PLANEJAMENTO DAS ATIVIDADES}

O primeiro resultado diz respeito ao planejamento construído pelo grupo de trabalho. O ponto de partida foi a consideração de que a prescrição descrita num currículo não determina o processo de aplicação deste. Assim, a prática docente entendida nos moldes de Bernstein (1996) como um espaço de recontextualização e ressignificação motivou a organização do grupo de trabalho, no sentido de que as reuniões foram desenvolvidas com a perspectiva de que o professor fosse o protagonista do processo.

$\mathrm{O}$ professor A foi chamado a assumir turmas de primeira série do Ensino Médio no mês de agosto, iniciando suas atividades de docência no terceiro bimestre. Essas turmas até então não haviam tido aulas de Física. Em resumo, o professor A tinha diante de si o desafio de implementar o CMF a partir do terceiro bimestre com um grupo de alunos que não estudara Física até então. Ele trouxe a problemática para o grupo de trabalho com a convicção de que deveria seguir a prescrição do CMF (2012) para o terceiro bimestre. Essa questão foi debatida no grupo de trabalho, que considerou viável a proposta do professor $\mathrm{A}$.

Considerando que a TRR era o tema a ser desenvolvido, o grupo de trabalho baseou-se numa revisão bibliográfica prévia, que levantara artigos de periódicos - CBEF, RBEF, Física na Escola) -, artigos de congresso, dissertação e paradidáticos que apresentavam propostas e reflexões sobre o estudo da TRR na educação básica. 
Essa revisão foi o ponto de partida para o desenho de uma estratégia didática que pudesse levar em conta os resultados provenientes da pesquisa em ensino, tanto do ponto de vista dos subsídios presentes, quanto da coerência em relação aos objetivos educacionais.

No grupo de trabalho desenhamos, então, uma sequência de quatro aulas, de 90 minutos cada, a se desenrolar em quatro semanas, visto que o terceiro bimestre continha ao todo cinco aulas, e era necessário reservar espaço para as avaliações. Nesse sentido, observamos a necessidade de fazer um recorte, de estabelecer prioridades. A opção por restringir a abordagem à TRR, explorando mais os conceitos de espaço, tempo e velocidade relativa, foi realizada pelo professor A nas reuniões de planejamento anterior ao início da sequência didática. Essa opção ocorreu a partir do confronto entre a situação daqueles alunos com o estudo que o professor A realizara sobre o tema na graduação e no grupo de trabalho. Durante as reuniões, o professor A sempre ponderou que no planejamento deveriam ser escolhidos atividades, imagens e exemplos ligados ao dia a dia dos alunos. Essa posição acabou direcionando a discussão do grupo de trabalho, de forma que ao final a proposta era que a apresentação da TRR com base nas discussões de tempo e espaço fosse feita sem vinculá-las à questão do éter e, portanto, ao experimento de Michelson-Morley.

A ponderação do professor A em usar sistematicamente exemplos do cotidiano dos alunos como elemento introdutório das aulas, com vistas a motivá-los, foi problematizada no grupo de trabalho. As pesquisadoras encaminharam discussões, buscando destacar a importância de que, além da motivação, houvesse a preocupação em trazer à sala de aula discussões que possibilitassem aos alunos construir uma visão mais crítica da ciência. Nesse ponto, as pesquisadoras destacaram que tal preocupação vai ao encontro da proposta do CMF (2012), que aborda no primeiro e segundo bimestres as visões aristotélica e newtoniana do universo físico, descrevendo competências ligadas a uma compreensão da ciência como construção humana. O tratamento da TRR no terceiro bimestre vem no bojo dessa mesma ideia e pretende construir uma terceira visão de universo físico, a partir do confronto entre o paradigma newtoniano e as ideias de Einstein (RIO DE JANEIRO, 2012).

A necessidade de fazer escolhas levou o professor A juntamente com o grupo de trabalho a priorizar as competências ligadas à compreensão da ciência como construção humana, no sentido de enfatizar o caráter de ruptura e a construção coletiva da referida teoria. Dessa forma, houve uma preocupação das pesquisadoras de trazer ao professor material de apoio para o desenvolvimento de discussões históricas que permitissem enfatizar os tópicos selecionados.

O grupo de trabalho desenhou, então, para a primeira aula, uma abordagem resumida que viesse apresentar as visões de mundo de Aristóteles, bem como o confronto entre os modelos geostático e heliostático. Ainda nessa aula seriam abordados os esforços de Galileu em compreender a relatividade do movimento, a fim de argumentar a favor do modelo heliostático. Por fim, a aula apresentaria a relatividade de Galileu, já preparando o terreno para a introdução da TRR.

Uma segunda aula seria dedicada à compreensão mais aprofundada da relati- 
vidade de Galileu com a realização de atividades com bolinhas. Nessa etapa, se pretendia fazer uso de um ferramental matemático na manipulação de velocidades médias e velocidades relativas em movimentos à velocidade constante.

Em um terceiro momento seriam explorados mais a fundo os conceitos de espaço e tempo, discutindo esses temas também nas artes plásticas (GUERRA; BRAGA; REIS, 2006). A partir daí seria retomado o contexto do fim do século XIX e início do século XX no que concerne às noções de tempo e espaço na pintura e, ainda, à questão da marcação do tempo e à simultaneidade (GUERRA; BRAGA; REIS, 2010).

A quarta aula seria dedicada à compreensão da velocidade da luz como uma velocidade não relativa, mas absoluta, como postula a TRR e as consequências disso. A partir da abordagem do exemplo do trem viajando com um pulso de luz vertical, seriam abordadas as concepções de tempo e espaço relativo, deduzindo a equação da dilatação do tempo, e finalizando com a discussão do paradoxo dos gêmeos.

A realização do planejamento em si já aponta elementos importantes para a nossa análise. Em primeiro lugar por que o professor toma para si o desafio de trabalhar a TRR no EM apesar de todas as condições adversas que se impõem. Embora o professor A reconheça todas as limitações e dificuldades da sua situação específica, ele as toma como elementos motivadores.

Importante destacar que a situação aqui desenhada é favorável à mudança no sentido de que há um grupo trabalhando na busca de subsídios para a criação de uma nova abordagem e, nesse sentido, podemos dizer que o professor é assistido pelo grupo de trabalho. Isso, no entanto, não implica na situação de um professor técnico, executor de tarefas e soluções criadas por terceiros. O professor é um autor no grupo de trabalho/pesquisa, e isso é o que permitirá que ele recrie, na sua prática, as possibilidades de enfrentar um desafio que ele tomou para si.

Como exemplo da dinâmica de trabalho, podemos citar a preparação da primeira aula, na qual o professor A ficou na incumbência de confeccionar previamente os slides. Durante a discussão dos slides no grupo, o professor A acatou a sugestão de outros membros do grupo de trabalho e reconstruiu os slides deixando apenas as informações iniciais, de forma a abrir espaço para as manifestações dos alunos e, portanto, para um maior diálogo em sala de aula.

Nesse sentido, destacamos que o novo currículo acabou criando uma situação desafiadora, adversa, porém instigante, na qual o professor recém-formado vê uma possibilidade de criação. E é a partir desse desafio, com a assistência do grupo de trabalho, que o professor toma para si a missão de pôr em prática, pelo menos em parte, a prescrição presente no currículo.

\section{O PROFESSOR EM PRÁTICA}

Registramos as aulas planejadas em áudio e vídeo. A tomada em áudio e vídeo nos possibilitou ampliar a capacidade de observação dos episódios de ensino que foram revistos várias vezes. A gravação se deu por meio de uma única câmera fixa locali- 
zada em frente ao lugar onde a aula estava ocorrendo, uma vez que o foco da pesquisa está predominantemente no professor.

A partir da análise dos registros foi possível produzir uma narrativa das aulas, bem como transcrever trechos de falas do professor A e de alguns alunos que interagiram durante a aula. Alguns episódios de ensino merecem destaque e permitem-nos constatar a partir da prática docente elementos de ressignificação do currículo.

$\mathrm{Na}$ primeira aula, conforme o planejado, o professor utiliza uma projeção multimídia de slides previamente preparada e discutida no grupo de trabalho. O professor inicia a aula mencionando que:

Professor: A origem da Física está no momento em que o homem começou a se perguntar como é o mundo... Então, desde mais de dois mil anos pra cá... e é isso o que a gente vai discutir aqui.

Nesse contexto o professor menciona Aristóteles e a busca por explicações para os movimentos aparentes dos astros no céu e dos objetos aqui na Terra. Introduz então a questão da queda dos corpos e pergunta aos alunos por que os corpos caem:

\author{
Professor: Por que esse corpo cai? \\ Aluno A: Porque ele é pesado! \\ Professor: E se ele fosse leve? \\ Aluno A: Ele ia ficar no alto! \\ Professor: Ele ia ficar no alto? Flutuando pra sempre? \\ Alunos: (risos)
}

A partir desse diálogo, o professor faz o paralelo da fala do aluno com as ideias de Aristóteles. Em seguida, ele passa à descrição do universo segundo Aristóteles, sempre com o auxílio dos slides contendo charges e figuras.

Alguns alunos inclusive mencionam a sua conclusão de que esse universo apresentado é diferente daquele que eles aprenderam em Geografia, pois lá "é o Sol que está no centro".

A partir de uma figura representativa da visão de mundo aristotélica e da afirmação dos alunos de que o Sol é que está no centro do universo, o professor encaminha uma discussão sobre os possíveis efeitos de a Terra estar em movimento. Destaca que o movimento aparente dos astros parece indicar que tudo se move ao redor da Terra e, além disso, não sentimos que estamos em movimento. A partir daí, com a ajuda de figuras representativas, explana sobre Copérnico, Galileu e usa referência aos Diálogos sobre os dois máximos sistemas de mundo de Galileu para descrever o exemplo dado pelo italiano com o movimento de corpos no interior de um navio.

Dessa explanação, o professor encaminha o questionamento de por que não sentimos estar em movimento na Terra e em outras situações. Propõem um "experimento de pensamento" no qual uma pessoa seria induzida a dormir e colocada em um avião, com as janelas todas fechadas. 
Professor: vamos dizer que eu pego você dormindo e te coloco dentro de um avião... o avião decolou com você dormindo e o avião está lá em cima com você dormindo. Aí você vai e acorda. Se você não abre a janela do avião, você consegue dizer se o avião está em movimento? Aluno C: Mas é que daí ele balança assim né?

Professor: Mas o avião está em movimento? Isso se tiver uma zona de turbulência, mas se não tiver o avião não se mexe...

Aluno D: Se não abrir a janela não dá pra saber...

Professor: A velocidade de um avião é de aproximadamente $800 \mathrm{~km} / \mathrm{h}$, e mesmo assim você não consegue perceber o movimento!

Em seguida, o professor propõe uma atividade para que os alunos façam no ônibus ao voltar para casa:

Professor: Joga um objeto pra cima e vê se ele não cai na mão de vocês.

Aqui, embora o contexto seja da abordagem histórica inicial, o professor A durante a aula enfatizou exemplos cotidianos dos alunos e deu destaque a pontos que preparassem o terreno para o estudo da TRR. Nesse sentido, destacamos que, apesar do planejamento e da existência de uma sequência de conteúdo a ser seguida, as ênfases e omissões já refletem o objetivo maior do professor. Dentre os vários conteúdos que compreendem o tema velocidade, ele escolhe dedicar mais tempo de aula com mais exemplos e explicações para a questão da velocidade relativa. Isso revela elementos da recontextualização que ele, como protagonista, realiza, a despeito de as discussões no grupo de trabalho terem sido mais enfáticas em relação ao caráter histórico do episódio.

Dando sequência à aula, o professor começa a problematizar o próprio conceito de velocidade perguntando aos alunos o que significa estar a $1 \mathrm{~m} / \mathrm{s}$. Os alunos parecem não entender a pergunta. Então o professor reformula:

Professor: Quanto tempo eu levo pra andar $10 \mathrm{~m}$ a essa velocidade?

Alguns alunos respondem que levaria $10 \mathrm{~s}$. O professor aponta um aluno parado e enfatiza:

Professor: eu andei em relação a ele certo? Imagine agora que ele está em um carro e eu em outro. O carro da frente está marcando $80 \mathrm{~km} / \mathrm{h}$ e o carro de trás está marcando $80 \mathrm{~km} / \mathrm{h}$, quando vocês olham o primeiro, vocês veem ele a mais de oitenta, menos de oitenta ou oitenta?" [...] "E se um carro estiver do lado do outro?"

Aluno A: Parece que tá parado.

Professor: então o movimento não é relativo?

Aluno A: É. Às vezes vai parecer em movimento, às vezes vai parecer que ele está em repouso.

Nesse episódio fica nítido que, apesar da dificuldade de trabalhar com o conceito da velocidade apenas com a noção advinda do senso comum dos alunos, o professor A insiste nesse caminho. Ao final, ele abandona a discussão, justificando em sua fala que, na aula seguinte, poderá se debruçar mais especificamente sobre o conceito.

Ainda para finalizar a primeira aula, o professor faz uso de um vídeo que ilustra o princípio da relatividade de Galileu, por meio de desenhos esquemáticos e 
animados com movimentos de carros e árvores. O professor ainda usa o recurso de uma tirinha que ironiza a contradição de mundo de Aristóteles e Galileu em relação ao movimento da Terra. A primeira aula chega ao fim.

Desse primeiro encontro, podemos perceber que o professor se apropria de algumas das discussões travadas no grupo de trabalho, como as da contradição entre os modelos de mundo de Aristóteles e Galileu. Porém, durante sua prática, cria exemplos e explicações não previamente acordadas com o grupo de trabalho, como o do avião, e busca sentidos que aproximem o conhecimento da realidade dos alunos, por exemplo, quando pede que eles façam uma "experiência" no ônibus ao voltar para casa. Podemos interpretar isso como uma recontextualização, sobre a qual ele já dava sinais desde as discussões do planejamento.

A segunda aula se inicia com uma retomada das concepções de universo, abordadas na aula anterior, de Aristóteles e Galileu. O professor expõe aos alunos a necessidade que ele percebeu na aula anterior de explorar melhor os conceitos de velocidade e velocidade relativa:

Professor: terminamos falando da concepção de movimento... notei que a coisa da velocidade está meio embolada pra vocês... então vou retomar.

Assim, o professor retoma a questão da velocidade média de forma bastante paulatina, a partir do exemplo de uma viagem com um carro a $100 \mathrm{~km} / \mathrm{h}$. O professor define ainda de forma bem incisiva o conceito de velocidade constante, diferenciando-a do conceito de velocidade média.

Em seguida, o professor propõe uma atividade, que foi previamente sugerida e discutida no grupo de trabalho, na qual divide os alunos da sala em dois grandes grupos e dá a cada um uma bolinha de pingue-pongue e uma trena. Pede que eles escolham uma pista e registrem numa tabela as distâncias percorridas e os instantes de tempo correspondentes. Os alunos tomaram a iniciativa de usar seus celulares como cronômetros. Os alunos se envolveram na atividade e se dividiram para fazer as medidas que o professor anotava no quadro.

O professor intervém ao perceber problemas em relação às unidades utilizadas e faz uma breve explanação sobre a transformação quilômetro-metro e minuto-hora-segundo. Em seguida, os alunos finalizam a construção das tabelas de distância percorrida por tempo.

Antes de efetuar as operações matemáticas que gerariam valores de velocidade, o professor pede que os alunos tirem conclusões fazendo estimativas.

Professor: Qual andou mais devagar? Foi a mesma distância, mas um gastou a metade do tempo...

Aluno E: O outro foi mais rápido.

Professor: Ok. Agora podem fazer a conta. 
Após aparecerem os primeiros resultados calculados pelos alunos, o professor problematiza o significado do valor encontrado de $38 \mathrm{~cm} / \mathrm{s}$.

Em seguida, o professor pergunta aos alunos o que aconteceria se uma das bolinhas começasse a se mover em direção à outra. Pergunta se elas demorariam mais ou menos para se encontrarem. Alguns alunos bradam "mais" e outros bradam "menos".

O professor, então, para e faz uma analogia com pessoas em movimento, envolvendo uma aluna e ele, contando passos e marcando o tempo com palmas. A partir daí faz uma nova tabela, calcula a distância percorrida pelos dois e o tempo. $\mathrm{O}$ professor introduz então o conceito de soma de velocidades e explora a questão da relatividade da velocidade de um objeto se movendo em relação a outro. Aqui temos outro episódio que evidencia o caráter de criação na prática, revelando que o professor cria, quase que de forma improvisada, uma nova estratégia com as palmas, para atingir objetivos definidos no grupo de trabalho, mas não considerados por ele alcançados pela estratégia inicial.

Na reunião do grupo de trabalho após a segunda aula, o professor A explicitou o porquê das ênfases e omissões desenvolvidas ao longo da aula. O professor A apontou que estava preocupado na construção de conceitos que seriam retomados na abordagem da TRR.

O professor A destacou no grupo de trabalho que, na prática, foi possível abordar o conceito de velocidade dedicando um tempo relativamente pequeno para tal. Deve-se destacar que a cultura didática da Física tradicional costuma dedicar muito tempo e promover uma exaustiva resolução de exercícios ligados ao conceito de velocidade, antes que se possa ir adiante na abordagem de outros conhecimentos. A clareza em relação aos objetivos finais de ensino estabeleceu a necessidade da compreensão do conceito de velocidade, porém, o professor A abordou o tema de forma sucinta, sem referências a resoluções de exercícios clássicos, rompendo de certa forma com a cultura didática da Física tradicional.

Embora a ênfase dessa pesquisa esteja centrada no professor, e que não tenhamos elementos suficientes para fazer afirmações convincentes sobre a aprendizagem dos alunos, podemos perceber que o objetivo do professor A no que concerne à compreensão por parte dos alunos do conceito de velocidade parece se cumprir, na medida em que ele percebe que construiu uma noção do conceito que lhe permitirá ir adiante no desafio de abordar a TRR.

$\mathrm{Na}$ terceira aula, o professor A parte direto para a discussão da relatividade do espaço:

Professor: o espaço é absoluto como o tempo ou não? Se eu tiver um metro desses de pedreiro e eu estiver parado fazendo essa medida, ou se eu estiver andando e fazendo essa medida, é a mesma coisa?

Em seguida, ele coloca dois alunos para andarem em direções diferentes, um em direção ao final da sala e outro ao longo do quadro.

Professor: E se os dois saírem andando na mesma velocidade? Agora vamos supor que eu tenho certeza de que eles têm a mesma velocidade. Se o espaço é o mesmo pra 
todo mundo e o tempo é o mesmo pra todo mundo, seria possível eles chegarem ao mesmo tempo nesses dois pontos? Ele chega aqui (ponto mais próximo) no mesmo instante que ela chega lá (ponto mais distante na sala)?

Alunos: Acho que não. Acho que não, hein!

Professor: E se trocar eles de posição?

Aluno D: Ela chega primeiro!

Professor: Vai conseguir chegar ao mesmo tempo ou não vai conseguir chegar ao mesmo tempo?

Alunos: Não vai! Ela vai chegar primeiro!

Professor: Então pelas leis que nós discutimos aqui, ou seja, que o espaço é absoluto e que o tempo é absoluto é impossível a eles chegar junto.

O professor conduz a aluna ao fim do percurso mais próximo enquanto fala:

Professor: Vamos imaginar agora que a gente está num outro mundo com regras totalmente diferentes das nossas, ou seja, vamos rasgar as leis da Física, e que eu comecei a contar um, dois, três, quatro, cinco. E aí vamos supor que dali a algum tempo ela veio com essa velocidade e pá, encostou ali. E ele chegou e encostou lá no final. Qual seria o defeito se os dois tivessem chegado ao mesmo tempo?

Aluno C: A velocidade não ia ser igual, não, professor!

Professor: E se eu tivesse certeza de que a velocidade é a mesma? O tempo teria corrido igual para os dois? A distância seria a mesma para os dois?

Alunos: (silêncio)

Professor: Pra que isso acontecesse, se eu tenho certeza de que a velocidade é a mesma, eu teria que rasgar alguma coisa... Meu tempo absoluto e meu espaço absoluto. Ou seja, essa ideia de espaço que nós estamos vendendo aqui que foi a mesma que lá atrás Galileu concebeu poderia não ser absoluta...

A atividade aqui proposta pelo professor foi mais uma recriação daquilo que foi discutido no grupo de trabalho. A partir da atividade com passos e palmas, que lhe pareceu bem-sucedida na aula anterior, o professor A criou com os alunos a ideia de um mundo diferente do nosso, diferente do espaço tempo em que vivemos. Introduz sutilmente a ideia de que adentrar ao mundo relativístico é algo como acessar outras regras da Física. Isso tem coerência com a premissa de ensinar uma Física com contradições, controvérsias e várias visões de mundo, mas não conjuga com a cultura didática de sua disciplina.

Dando sequência à aula, o professor inicia uma explanação sobre algumas discussões sobre o tempo que aconteceram no fim do século XIX e início do século XX:

Professor: No finalzinho de 1800, começo de 1900, coisa de uns cento e poucos anos atrás, aconteceu uma discussão a respeito da questão de tempo. Um problema que se tinha na época é quando você queria acertar um relógio você ia na frente da igreja e acertava o relógio. No caso, vocês iriam na igreja aqui de Pedro do Rio... Se você estivesse em Corrêas, você iria na igreja de Corrêas. O que acontecia lá na época é que eles não tinham a facilidade de comunicação que a gente tem hoje, então, coisa do simultâneo, ou seja, de mesmo instante, era meio complicado pra eles. Porque como que você ia garantir que esse relógio da igreja aqui de Pedro do Rio está certinho com 
a igreja de Corrêas, se você não tem telefone? Tinha como eles garantirem isso? Não tinha! Então o que acontecia na época era que o tempo era local. Ou seja, o tempo que você tinha dependia do lugar em que você estava. O tempo, a hora local do relógio que eu tinha. E não tinha problema nenhum porque se você marcasse um encontro às cinco horas da tarde com uma menina em Pedro do Rio, vale a hora em Pedro do Rio! Se você marcasse pra fazer um pagamento em Petrópolis, valeria a hora de lá! Como não tinha celular... hoje é fácil, tu pega o celular e liga pra uma pessoa de Corrêas e pergunta: que horas são aî́? E a gente sabe que tá no mesmo horário, mas na época não tinha isso. Cada região, cada vilarejo tinha seu tempo próprio. Só que o que começa a acontecer? Os transportes começam a ficar mais ágeis... Os trens começam a ficar mais rápidos... E na linha férrea é a mesma linha que o trem usa pra ir e pra voltar. Então se você não tiver uma sincronia na questão do tempo o que é que pode acontecer? Aluno E: Pode dar uma batida e matar um monte de gente!

Professor: Exato! E os trens não saem do mesmo lugar então... O horário local é diferente e surge essa preocupação com a questão do tempo da sincronia.

Aqui percebemos que o professor se apropriou de parte das discussões presentes na bibliografia estudada no grupo de trabalho e recriou essas discussões em narrativas de sala de aula. Como exemplo, citamos a questão dos trens presentes em Galison (2005) e discutidas no grupo de trabalho. E mais uma vez percebemos que, ao mesmo tempo, o professor A se apropria de referências apresentadas a ele no grupo de trabalho e as recontextualiza, inclusive, usando exemplos locais e lugares conhecidos do cotidiano dos alunos.

O professor A, então, mencionou a concepção de espaço pela arte, algo também discutido no grupo de trabalho. Explanou sobre a função das pinturas como representação que retrata cenas e pessoas e da mudança desencadeada pelo aparecimento da máquina fotográfica. A fotografia permitiu o registro antes restrito aos artistas. $\mathrm{O}$ professor destacou essas questões e que essas mudanças acabaram por desencadear novas formas de representação pictórica. Explicou que nessa época a pintura passou a ir além da imagem representativa, criando imagens e realidades distorcidas. Destacou que isso deu espaço para interpretar que tinha gente "começando a enxergar diferente a coisa do tempo e espaço" (professor).

Essa discussão também reflete apropriação de parte da bibliografia estudada no grupo de trabalho (GUERRA; BRAGA; REIS, 2006).

$\mathrm{Na}$ sequência da aula, o professor comentou rapidamente que na ciência começaram a surgir alguns "probleminhas" em relação à velocidade da luz. Comentou que de algumas equações do eletromagnetismo surgiu um resultado que mostrava uma constante que tinha valor coincidente com o estabelecido na época para a velocidade da luz:

Professor: Quando aparece esse resultado pra ele (Maxwell), a primeira pergunta que vem é "essa velocidade é em relação a quê?". Por que a velocidade não é relativa? A gente não viu que a velocidade depende de quem está observando? Então aquela velocidade aí vai depender em relação a quem. Em relação à Terra que está se movimentando? Em relação ao Sol, em relação à Lua, em relação a quem? A velocidade muda de um observador pra outro?

Alunos: Muda! 
Professor: Começam a aparecer vários pensadores da época tentando fazer estudos em relação a qual é essa velocidade. E os estudos vão surgindo, e as pessoas não querem abrir mão de que velocidade é relativa. E isso é o que a gente sabe! E quanto mais começam a mexer com isso, mais difícil vai ficando achar em relação a que que a luz se move a $300000 \mathrm{~km} / \mathrm{s}$ [A29]. Aqui a gente fica sobre um tripé. A questão do espaço está sendo discutida na arte, está se buscando soluções para a questão do tempo, por conta dos trens, e o pessoal começa a fazer estudos sobre a velocidade da luz e não consegue achar a relatividade da velocidade. Aí aparece um tal de Einstein...

Nesse ponto, o professor explanou brevemente sobre a história de Einstein, ressaltando que ele trabalhava em um escritório de patentes e explicando o que é isso. Ele deu ênfase ao brilhantismo dos trabalhos de Einstein, mas não deixou de comentar que muitas ideias estavam presentes à época.

Esse episódio ressalta uma interessante dinâmica do processo de recontextualização, uma vez que o professor hibridizou ideias e concepções discutidas no grupo de trabalho com imagens sobre o conhecimento construídas talvez em sua formação, sob um viés mais tradicional. Isso, inclusive, no que concerne à própria história da ciência, uma vez que na apropriação acabou fazendo colocações incoerentes com a bibliografia discutida no grupo. Maxwell, no estudo do eletromagnetismo, trabalhou com situações de movimento do ímã em relação à bobina e vice-versa, mas, por tomar o éter como referencial absoluto, não analisou esses casos à luz da relatividade estabelecida pela mecânica galileana, como o professor A dá a entender em sua explicação.

Nessa aula, percebemos que o professor estabeleceu elementos de ruptura com a cultura tradicional ao mencionar o conceito de tempo no final do século XIX e ao fazer relação com outras áreas como a arte.

Por outro lado, ele se remeteu também ao éter, apesar de no planejamento inicial este ter sido um elemento considerado desnecessário, e a figura de Einstein como alguém especial, recriando na prática elementos da cultura tradicional da didática da Física.

$\mathrm{Na}$ última aula programada para a sequência, o professor iniciou recebendo os trabalhos dos alunos e discutindo o paradoxo dos gêmeos. Com ajuda de slides com desenhos da "nave viajante" e do movimento relativo entre uma espaçonave e a Terra, ilustrou qual é o paradoxo envolvido. Após isso retomou a discussão sobre o tempo absoluto com os alunos:

Professor: O tempo é constante, igual pra todo mundo? Você tinha afirmado que ele era absoluto numa aula anterior?

Aluno E: Mas agora eu acho que não é!

Professor: Pra quem o tempo passa mais devagar? Pra quem tá em alta velocidade ou pra quem está parado?

Aluno D: Pra quem está em alta velocidade!

Ainda fazendo o uso do projetor multimídia, o professor mostrou algumas obras de arte, comentando a figura da pintura impressionista Maria Madalena Meditando e fazendo outras discussões sugeridas em Guerra, Braga, Reis (2006), a respeito das representações de tempo presentes na pintura do período do fim do século XIX até o começo do século XX. O professor encerrou o assunto comentando que:

Professor: Einstein não está começando a fazer nada sobrenatural, e sim está come- 
çando a fazer coisas que estão bem de acordo com a sua época.

Essa fala do professor conjuga questões debatidas no grupo de trabalho, no sentido de destacar que o trabalho de Einstein é fruto de uma época, com estreita ligação ao contexto sociocultural de sua produção. Essa fala se distancia daquela destacada na descrição da terceira aula, em que o professor afirmou ser Einstein alguém especial e genial. Isso corrobora ainda mais a ideia da ressignificação, na qual, na prática, podem coexistir visões bastante distintas e até contraditórias, conciliadas para atender a uma finalidade ou objetivo educacional.

\section{CONSIDERACְ̃̃ES FINAIS}

Confrontando-nos diretamente com a nossa pergunta de pesquisa, podemos dizer que várias ressignificações foram reconhecidas durante as aulas nas quais o professor se propôs a implementar o currículo. Além disso, a abordagem desenhada pelo professor A mostrou momentos de ruptura com a cultura escolar da Física, pois a Física não foi apresentada apenas como um conjunto de verdades definidas. Além disso, ele não trabalhou com muitos exercícios e fez recortes bem diferenciados, que incluíram interseções com a história e a arte.

Embora o CMF (2012) já traga uma inovação e uma ruptura com as sequências tradicionais de conteúdos mais características de uma cultura didática da Física, muito se questiona sobre a exequibilidade da proposta. Isso tanto do ponto de vista das omissões e inclusões, quanto do confronto com a cultura escolar típica dos professores de Física. No Estudo de Caso em questão, o professor A trabalhou o conteúdo novo da TRR, e isso foi possível a partir de um contexto que deu suporte e incorporou o professor como ator de um grupo de trabalho/pesquisa no qual ele foi o protagonista, recriando na sua prática de sala de aula os estudos e discussões iniciados no grupo.

Com os olhares voltados à prática docente, entendido como espaço de ressignificação, e não apenas de aplicação de mudanças pensadas por outros, encontramos vários episódios onde é nítida a ação recriadora do sujeito. A partir de um olhar mais abrangente, podemos perceber o quanto as missões pessoais e as experiências do sujeito foram determinantes nas escolhas feitas e nas ênfases e omissões.

A vivência do professor A apontou claramente para um interesse maior na questão da FMC no EM. E esse parece ser o caráter maior de suas ações como professor a despeito de o currículo prescrito e das intervenções do grupo de trabalho apontarem caminhos mais ligados à História da Ciência. Assim, nossos resultados apontam de forma clara tanto para o protagonismo do professor, quanto para a dinâmica de construção de significados que acontece na prática.

\section{REFERÊNCIAS}

ALVES-MAZOTTI, A. J. Uso e abuso dos Estudos de Caso. Caderno de Pesquisa, São Luiz, v. 36, n. 129, p. 637-651, 2006.

ANDRÉ, M. E., DALMAZO, A. Estudo de caso: seu potencial na educação. Caderno de pesquisa, São Luiz, n. 49, p. 51-54, 1984. 
BARCELLOS, M. E. Conhecimento e currículo: problematizando a licenciatura em física. 2013. 257 f. Tese (Doutorado Ensino de Ciências) - Universidade de São Paulo, São Paulo, 2013.

BERNSTEIN, B. A estruturação do discurso pedagógico: classe, códigos e controle. Petrópolis: Vozes, 1996.

BRUNER, J. O processo da educação. São Paulo: Nacional, 1987.

CHERVEL, A. História das disciplinas escolares: reflexões sobre um campo de pesquisa. Teoria e Educação, Goiânia, n. 2, p. 177-277, 1992.

CHEVALLARD, Y. La transposición didáctica: del saber sabio al saber enseñado. Buenos Aires: Aique, 1998.

EIJKELHOF, H.; KORTLAND, K.; LOO, F. V. D. Nuclear weapons: a suitable topic for the classroom? Physics Education, 19, p. 11-15, 1984. Special issue.

FOURQUIN, J-C. Escola e cultura: as bases epistemológicas do conhecimento escolar. Porto Alegre: Artes Médicas, 1993.

GALISON, P. Os relógios de Einstein: o lugar do tempo. Revista Ciência e Ambiente, Santa Maria, v. 30, p. 7-34. 2005

GOODSON, I. As políticas de currículo e de escolarização. Petrópolis: Vozes, 2008.

GUERRA, A.; BRAGA, M.; REIS, J. C. 2006. Ciência e arte: relações improváveis? Hist. Cienc. Saúde, Manguinhos, v. 13, out./dez, 2006.

GUERRA, A.; REIS, J. C.; BRAGA, M. 2010. Tempo, espaço e simultaneidade: uma questão para os cientistas, artistas, engenheiros e matemáticos no século XIX. Caderno Brasileiro de Ensino de Física, Florianópolis, v. 27, issue 3, p. 568-583, 2010.

LOPES, A. C. Políticas de integração curricula Rio de Janeiro: UERJ, 2008.

LOPES, A. C; MACEDO, E. Teorias de currículo. São Paulo: Cortez, 2011.

LUTZ, L.; BARCELLOS, M.; GUERRA, A. 2012. Mudança Curricular no Estado do Rio de Janeiro e a Física Moderna e Contemporânea. Maresias: EPEF, 2012. Disponível em: <http://www.sbf1.sbfisica.org.br/eventos/epef/xiv/sys/resumos/T0189-1.pdf.>. Acesso em: 25 abr. 2014.

LUTZ, L.; BARCELLOS, M.; GUERRA, A. 2013. Relatividade Restrita no Ensino Médio: existem subsídios para o professor? In: Atas do IX ENCONTRO NACIONAL DE PESQUISA EM EDUCAÇÃO EM CIÊNCIAS. Águas de Lindoia: ABRAPEC, p. 807-815, 2013.

MARTINS, A. F. P. História e filosofia da ciência no ensino: há muitas pedras nesse caminho. Caderno Brasileiro de Ensino de Física, v. 24, n. 1, Florianópolis, p. 112-131, 2007.

MONTEIRO, R. A física moderna e contemporânea e o currículo: Análise de uma postura docente. Monografia de licenciatura em Física no CEFET/RJ Petrópolis: CEFET/ RJ, 2013.

MORAIS, A.; GUERRA, A. História e a filosofia da ciência: caminhos para a inserção de temas física moderna no estudo de energia na primeira série do Ensino Médio. Revista Brasileira de Física, Florianópolis, v. 35, n. 1, p. 1502-1-1502-9, 2013. 
PINTO, A.C.; ZANETIC, J. É possível levar a Física Quântica para o ensino médio? Caderno Catarinense de Ensino de Física, Florianópolis, v. 16, n. 1, p. 7-34, abr. 1999.

RIO DE JANEIRO. Secretaria de Estado de Educação. Currículo Mínimo 2012 - Física. Rio de Janeiro: SEEDUC, 2012.

SCHÖN, D. The reflective practioner. How professionals think in action. Londres: Temple Smith, 1983.

SILVA, J. R. N. da; ARENGHI L. E. B.; LINO, A. Porque inserir física moderna e contemporânea no ensino médio? Uma revisão das justificativas dos trabalhos acadêmicos. R. B. E. C. T., v. 6, n. 1, jan-abr.2013.

SILVA, C. S., ALMEIDA, M. J. P. M. Física quântica no ensino médio: o que dizem as pesquisas. Caderno Brasileiro de Ensino de Física, Florianópolis, v. 28, n.3, p. 624-652, 2011.

SOUZA, A. J.; ARAÚJO, M. S. T. A produção de raios X contextualizada por meio do enfoque CTS: um caminho para introduzir tópicos de FMC no ensino médio. Educar, Curitiba, v. 37 ,

p. 191-209, 2010.

TARDIF, M. Saberes docentes e atuação profissional. Rio de Janeiro: Vozes, 2010.

TYLER, R. Princípios básicos de currículo e ensino. Porto Alegre: Globo, 1989.

VALENTE, L et al. Física Moderna e Contemporânea no Ensino Médio: Expectativas e tendências. In: ENCONTRO NACIONAL DE PESQUISA EM EDUCAÇÃO EM CIÊNCIAS, 6., Belo Horizonte. Atas... Belo Horizonte: ABRAPEC, 2007.

Data recebimento: 25/04/2014

Data de aprovação: 27/03/2015

\section{Contato autor:}

Marcília Barcellos

Rua do Imperador, 971 - Centro, Petrópolis, Rio de Janeiro - Brasil

CEP: 25.620-003

E-mail: marcilia12@hotmail.com 